\title{
DEMANDA DE NUTRIENTES PELO MILHO SAFRINHA EM FUNÇÃO DA ÉPOCA DE SEMEADURA E ADUBAÇÃO ${ }^{1}$
}

\author{
EDUARDO DE PAULA SIMÃO², ÁLVARO VILELA DE RESENDE ${ }^{3}$, \\ MIGUEL MARQUES GONTIJO NETO ${ }^{3}$, EMERSON BORGHI', \\ DENIZE CARVALHO MARTINS ${ }^{2}$ e ÁLISSON VANIN ${ }^{4}$
}

\author{
${ }^{1}$ Parte da dissertação de mestrado, do primeiro autor, em Ciências Agrárias, pela Universidade Federal de São João Del Rei \\ ${ }^{2}$ Doutorando em Fitotecnia pela Universidade Federal de Viçosa. \\ e-mail: eduardosimao.agro@yahoo.com.br,denizecarvalhom@yahoo.com.br \\ ${ }^{3}$ Pesquisador da Embrapa Milho e Sorgo.e-mail: alvaro.resende@embrapa.br, \\ miguel.gontijo@embrapa.br,emerson.borghi@embrapa.br. \\ ${ }^{4}$ Pesquisadorda COMIGO.e-mail: alissonvanin@hotmail.com
}

Revista Brasileira de Milho e Sorgo, v.16, n.3, p. 481-494, 2017

\begin{abstract}
RESUMO - No Brasil Central, a produtividade e a demanda nutricional do milho em sucessão à soja cultivada no verão são dependentes das condições climáticas ao longo do ciclo. Sendo assim, objetivou-se com esse trabalho quantificar a extração e exportação de nutrientes pelo milho, em função da época de semeadura e da adubação fornecida na safrinha de 2014, em Rio Verde-GO. Em cada época de semeadura (29/01/2014 e 25/02/2014) foi conduzido um experimento em delineamento de blocos casualizados, com quatro repetições, num esquema fatorial $4 \times 2$, sendo quatro adubações de semeadura (00-00-00, 00-50-50, 25-50-50 e 50-50-50 kg ha-1 de $\left.\mathrm{N}-\mathrm{P}_{2} \mathrm{O}_{5}-\mathrm{K}_{2} \mathrm{O}\right)$, com ou sem adubação nitrogenada em cobertura (0 ou $\left.50 \mathrm{~kg} \mathrm{ha}^{-1} \mathrm{de} \mathrm{N}\right)$. Ao final do ciclo, foram avaliados o rendimento de grãos e o acúmulo de nutrientes nos componentes da parte aérea. Foram determinadas a extração e a exportação de nutrientes. O desenvolvimento e a extração de nutrientes pelo milho safrinha são influenciados pela época de cultivo, assim como pela adubação nitrogenada em cobertura, sem, contudo, ser afetados pela adubação NPK realizada na semeadura. Há maior produção de biomassa seca e produtividade de grãos com a semeadura em janeiro em comparação a fevereiro. O cultivo na primeira época e o nitrogênio em cobertura resultam em maior extração da maioria dos nutrientes, sem necessariamente implicar maiores taxas de exportação com a colheita dos grãos. Em média, a exportação por tonelada de grãos produzida foi de 14,2; 1,5;2,8; 0,07; 0,7 e 1,0 kg de N, P, K, Ca, Mg e S; e de 2; 12; 4 e $16 \mathrm{~g} \mathrm{de} \mathrm{Cu,} \mathrm{Fe,} \mathrm{Mn}$ e $\mathrm{Zn}$, respectivamente. Esses valores implicam doses relativamente baixas de fertilizantes na adubação de manutenção para repor a exportação na colheita do milho safrinha.
\end{abstract}

Palavras-chave: sucessão de culturas, extração, exportação, requerimentos nutricionais, Zea mays L.

\section{OFF-SEASON CORN NUTRIENT DEMAND ACCORDING TO THE SOWING DATE AND FERTILIZATION}

\begin{abstract}
In Central Brazil, productivity and nutritional demand of corn in succession to soybeans grown in summer are dependent on climatic conditions throughout the cycle. Therefore, the objective of this work was to quantify the extraction and exportation of nutrients by off-season corn, according to the sowing date and fertilization in Rio Verde, State of -Goiás, Brazil. In each sowing time (01/29/2014 and 02/25/2014), a randomized complete block design experiment was carried out, with four replications, in a $4 \times 2$ factorial scheme, with four sowing fertilizations (00$00-00,00-50-50,25-50-50$ and $50-50-50 \mathrm{~kg} \mathrm{ha}^{-1}$ of N-P $\left.\mathrm{O}_{5}-\mathrm{K}_{2} \mathrm{O}\right)$, with or without nitrogen fertilization $\left(0\right.$ or $50 \mathrm{~kg}^{-1}$ $\mathrm{N})$. At the end of the cycle, grain yield and nutrient accumulation in shoot components were evaluated. The extraction and export of nutrients were determined. The growing season and the sidedress nitrogen influence the development and extraction of nutrients by the off-season corn, without, however, being affected by the NPK fertilization at sowing. There is higher production of dry biomass and grain yield with sowing in January compared to February. First-season cultivation and sidedress nitrogen result in greater extraction of most nutrients, without necessarily implying higher export rates with grain harvest. On average, the export per ton of grain produced was $14.2,1.5,2.8,0.07,0.7$, and $1.0 \mathrm{~kg}$ for $\mathrm{N}, \mathrm{P}, \mathrm{K}, \mathrm{Ca}, \mathrm{Mg}$ and $\mathrm{S}$; and 2, 12, 4, and $16 \mathrm{~g}$ for $\mathrm{Cu}, \mathrm{Fe}, \mathrm{Mn}$ and $\mathrm{Zn}$, respectively. These values result in relatively low amounts of fertilizers in the maintenance fertilization to replace the nutrients exported by the grain harvest. Keywords: succession crops, extraction, export, nutrient requirements, Zea mays L.
\end{abstract}


A produção de milho safrinha apresenta risco em razão da deficiência hídrica que ocorre à medida que se aproxima o final do período chuvoso, que normalmente coincide com os estádios mais avançados da cultura, o que pode limitar substancialmente o seu potencial produtivo. Mesmo com a semeadura do milho safrinha sendo realizada em períodos recomendados pelo zoneamento climático, o potencial de rendimento é menor se comparado ao milho da safra de verão. O cultivo deve ser realizado em áreas com fertilidade adequada para atender o balanço financeiro, que não suportaria investimentos no manejo para construção da fertilidade (Coelho \& Resende, 2008). Sendo assim, a adubação na safrinha deve ser embasada conforme as taxas de extração e exportação de nutrientes, sendo estas influenciadas principalmente pela época de semeadura, que em última instância define as condições climáticas mais ou menos favoráveis que afetarão o potencial produtivo do milho (Cruz et al., 2011).

O manejo da adubação do milho safrinha em sucessão à soja tem sido basicamente relacionado ao fornecimento de nitrogênio $(\mathrm{N})$, fósforo $(\mathrm{P})$ e potássio (K). De acordo com Duarte \& Cantarella (2007), a sucessão soja-milho extrai grande quantidade de N, e a liberação do nutriente dos restos culturais da soja não é suficiente para atender a demanda do milho, havendo necessidade de suprimento via adubação. Os mesmos autores reforçam que P e K também são nutrientes com elevado requerimento na cultura do milho, sendo o primeiro por sua alta taxa de exportação nos grãos e o segundo pela grande quantidade extraída pela planta. Tais exigências são razoavelmente atendidas com a decomposição dos restos culturais da soja (Cruz et al., 2011) e com as reservas no solo oriundas do efeito residual das adubações. Contudo, não se justifica realizar o cultivo do milho safrinha sem a adição destes nutrientes, pois sua deficiência pode acarretar redução na produtividade e diminuição dos estoques existentes no solo, comprometendo o sistema de culturas como um todo. Sendo assim, a adubação deve ser suficiente para, pelo menos, repor as quantidades de nutrientes exportadas na colheita.

As taxas de extração e exportação de nutrientes pelo milho são variáveis, dependendo de diversos fatores. Assim, há informações sobre extração de N, P e K variando de 16,7 a 28; 2,3 a 4,5; e 14,1 a 20,8 $\mathrm{kg}$ por tonelada de grãos produzida, respectivamente (Coelho \& Resende, 2008; Roscoe \& Miranda, 2013; Duarte et al., 2013). Roscoe \& Miranda (2013) e Duarte et al. (2013) citam ainda valores de exportação de N, P e K de 15,0 a 15,8; 3,6 a 3,8; e 4,7 a 4,8 $\mathrm{kg} \mathrm{t}^{-1}$ de grãos, respectivamente.

Em função de dúvidas que ainda pairam com relação aos aspectos quantitativos da nutrição e da adubação do milho safrinha, o objetivo deste trabalho foi determinar a extração e a exportação de nutrientes por cultivos em duas épocas de semeadura, sob diferentes combinações de adubação NPK, na região de Rio Verde-GO.

\section{Material e Métodos}

Os experimentos foram conduzidos em duas épocas de semeadura na safrinha (29/01/2014 e 25/02/2014), em área experimental do Centro Tecnológico da Comigo (Cooperativa de Produtores do Sudoeste de Goiás), na cidade de Rio Verde-GO, com coordenadas: S $17^{\circ} 45.969^{\prime}$ e W $051^{\circ} 02.255^{\prime}$, a uma altitude média de $748 \mathrm{~m}$.

O solo da área experimental foi classificado como Latossolo Vermelho Distrófico, com textura argilosa e relevo com média ondulação, tendo sido cultivado com soja na safra de verão em 2013/2014. Em outubro de 2013, realizou-se a aplicação de 2,1 tonela- 
das de calcário dolomítico por hectare, buscando atingir $60 \%$ de saturação por bases. A adubação da soja consistiu de $400 \mathrm{~kg} \mathrm{ha}^{-1}$ do formulado NPK 02-20-18, obtendo-se produtividade média de 50 sacas por hectare. As condições da fertilidade do solo na camada 0 - $20 \mathrm{~cm}$ de profundidade, antes da instalação do experimento, eram: $\mathrm{pH}$ em água 5,8; matéria orgânica 2,5 dag $\mathrm{kg}^{-1}$; teores de Pe K (Mehlich 1) de 25 e $44 \mathrm{mg} \mathrm{dm}^{-3}$, respectivamente; $\mathrm{Ca}, \mathrm{Mg}, \mathrm{Al}, \mathrm{H}+\mathrm{Al}$ e CTC potencial de 2,$7 ; 0,9 ; 0,0 ; 4,7$; e 8,4 cmolc $\mathrm{dm}^{-3}$, respectivamente; saturação por bases (V\%) de 44; e teores de $\mathrm{Cu}$, $\mathrm{Fe}, \mathrm{Mn}, \mathrm{Zn}$ de 1,0; 37,8; 6,8; e 2,7 mg dm-3, respectivamente. Já a análise granulométrica apresentou 530 $\mathrm{g} \mathrm{kg}^{-1}$ de areia; $80 \mathrm{~g} \mathrm{~kg}^{-1}$ de silte e $390 \mathrm{~g} \mathrm{~kg}^{-1}$ de argila.

Para cada época de cultivo, utilizou-se o delineamento de blocos casualizados, num esquema fatorial $4 \times 2$, sendo os tratamentos constituídos por quatro opções de adubação NPK na semeadura (00-00-00, 00-50-50, 25-50-50 e 50-50-50 kg ha-1 de N- $\mathrm{P}_{2} \mathrm{O}_{5}$ $\mathrm{K}_{2} \mathrm{O}$ ), com ou sem adubação nitrogenada em cobertura (50 kg ha-1 de N) na forma de ureia. Foi semeado o híbrido DKB 310 PRO, utilizando-se uma semeadora de parcelas, em espaçamento de 0,5 m entre linhas, buscando-se um estande final de 60.000 plantas por hectare. As adubações com fósforo e potássio foram realizadas com o mecanismo adubador da semeadora, utilizando-se uma mistura dos fertilizantes superfosfato simples (fonte de $\mathrm{P}$ ) e cloreto de potássio (fonte de K). A adubação nitrogenada foi realizada conforme os tratamentos, com ureia distribuída manualmente nas linhas no momento da semeadura e em cobertura nas entrelinhas aos 15 dias após a semeadura (estádio V3).

As sementes foram tratadas manualmente com imidacloprido e tiodicarb (38 e 112 g, respectivamente, para 60.000 sementes). Por volta dos 15 dias após a semeadura, foram aplicados os herbicidas atrazine e tembotrione (1,5 e $100 \mathrm{~g} \mathrm{ha}^{-1}$, respectivamente), para controle de plantas invasoras, e os inseticidas imidacloprido e beta-ciflutrin (100 e $13 \mathrm{~g} \mathrm{ha}^{-1}$, respectivamente) para insetos pragas do início do ciclo. Foram também realizadas duas pulverizações de fungicida azoxistrobina + ciproconazol $\left(60+24 \mathrm{~g} \mathrm{ha}^{-1}\right)$, nos estádios V10 e VT (início do florescimento). Por fim, aos 60 dias após a semeadura, foram aplicados os inseticidas metomil e teflubenzurom (129 e $15 \mathrm{~g}$ ha $^{-1}$, respectivamente). Os dados de precipitação pluviométrica e temperatura durante a safrinha de 2014 são apresentados na Figura 1.

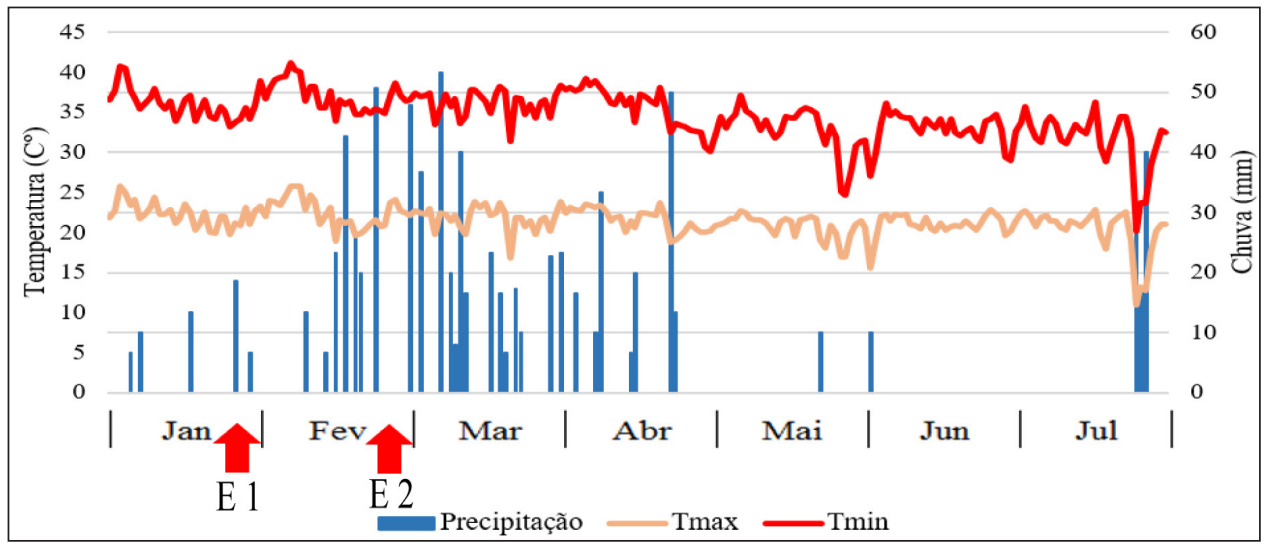

Figura 1. Dados de temperaturas máxima (Tmax) e mínima (Tmin) e de precipitação pluviométrica (mm) na área experimental, no período de janeiro a julho de 2014. As setas indicam as épocas de semeadura do milho safrinha em janeiro (E1) e fevereiro (E2). 
Cada parcela foi constituída de quatro linhas de cinco metros de comprimento, considerando-se como área útil as duas linhas centrais, descartando $1 \mathrm{~m}$ de cada extremidade, totalizando $3 \mathrm{~m}^{2}$ de área amostral. As colheitas foram realizadas em 24/06/2014 e $22 / 07 / 2014$, respectivamente, para as duas épocas de semeadura.

Foram coletadas 5 plantas inteiras por parcela para quantificação de nutrientes, separando-as em folhas, colmo, grãos, sabugo e palha. Esse material foi seco em estufa de ventilação forçada com temperatura entre 65 e $70{ }^{\circ} \mathrm{C}$ para determinação de massa seca. Posteriormente, foram analisadas as concentrações de macro e micronutrientes e carbono total, conforme Silva (2009). Os dados de massa seca e teores de nutrientes em cada compartimento foram utilizados para se estimar a produção de biomassa seca da parte aérea e a extração de nutrientes pela cultura. A partir dos teores nos grãos e das produtividades obtidas, foi calculada a exportação de nutrientes relacionada a cada tratamento.

Os dados foram submetidos à análise de variância conjunta para verificar a existência de intera- ção entre os tratamentos com diferentes adubações e épocas de cultivo. Para tanto, as duas épocas de cultivo foram incluídas dentre as fontes de variação na análise de variância. Quando significativo o efeito de tratamentos, utilizou-se o teste de Scott-Knott a 5\% de probabilidade para a comparação de médias, utilizando o programa SISVAR (Ferreira, 2011).

\section{Resultados e Discussão}

A análise de variância conjunta permitiu identificar que a época de cultivo (semeadura em janeiro ou em fevereiro) foi determinante na produção de biomassa seca e na produtividade de grãos (Tabela 1). A adubação nitrogenada em cobertura influenciou somente a produção de biomassa.

A primeira época de semeadura apresentou produtividade média de $8.736 \mathrm{~kg} \mathrm{ha}^{-1}$ de grãos, sendo estatisticamente superior à segunda época, que teve média de $6.949 \mathrm{~kg} \mathrm{ha}^{-1}$. Essa diferença correspondeu a $66 \mathrm{~kg} \mathrm{ha}^{-1}$ de grãos a menos por cada dia de atraso na semeadura, nas condições da safrinha de 2014 na região de Rio Verde-GO. Galvão et al.

Tabela 1. Resumo da análise de variância para produtividade de grãos e produção de biomassa seca total da parte aérea do milho safrinha.

\begin{tabular}{llll}
\hline Quadrado médio & & & \\
\hline F.V. & G.L. & Produtividade de grãos & Biomassa Seca Total \\
\hline Época-E & 1 & $51054543,0^{* *}$ & $120991970,1^{* *}$ \\
Repetição (E) & 6 & 623208,4 & 3368453,0 \\
NPK Semeadura-S & 3 & 592133,6 & 5214171,7 \\
N Cobertura-C & 1 & 935009,2 & $18339699,2 *$ \\
S x C & 3 & 1073622,0 & 1463146,3 \\
E x S & 3 & 2400019,1 & 2628498,3 \\
E x C & 1 & 369711,1 & 842177,9 \\
E x S x C & 3 & 1618932,5 & 1759876,1 \\
Resíduo & 42 & 1402218,3 & 3922123,5 \\
\hline Total & 63 & & \\
\hline C.V (\%) & & 15,10 & 13,17 \\
\hline
\end{tabular}

* e ** Significativo a 5 e $1 \%$ de probabilidade pelo teste $\mathrm{F}$. 
(2015) relataram que o atraso na semeadura pode reduzir a produtividade do milho safrinha em função das condições desfavoráveis do clima, com o fim do período de chuva. Nascimento et al. (2011) testaram três cultivares de milho em diferentes épocas de semeadura (agosto, outubro, dezembro e fevereiro) em Botucatu-SP e observaram que a semeadura realizada no mês de fevereiro apresentou menor produtividade de grãos em relação às demais. Segundo Vilhegas et al. (2001), à medida que se retarda a semeadura do milho safrinha, há redução da precipitação, da radiação solar e da temperatura durante o ciclo, causando queda da capacidade de produção da cultura.

É importante destacar que as limitações ao potencial produtivo do milho safrinha têm reflexos nas taxas de extração e exportação de nutrientes, as quais servem de critérios para o dimensionamento das adubações de manutenção. É de se esperar que a semeadura mais tardia implique menor absorção de nutrientes pela cultura, indicando a conveniência de reduzir o investimento em adubação à medida que se avança a data de semeadura. Os produtores em geral consideram essa possibilidade, mas nem sempre a redução da adubação se dá de forma proporcional à diminuição do potencial produtivo da lavoura semeada tardiamente. É comum simplesmente se dei- xar de adubar ou fazê-lo apenas parcialmente, fornecendo um pouco de nitrogênio. Esses procedimentos são reprováveis, pois, com o tempo, podem levar ao desbalanceamento entre as quantidades de nutrientes requeridas na sequência soja-milho safrinha (Kappes \& Zancanaro, 2014), prejudicando o desempenho do sistema como um todo.

A semeadura mais tardia, no fim do mês de fevereiro, restringiu o desenvolvimento das plantas de milho, resultando em decréscimo de $2,75 \mathrm{t} \mathrm{ha}^{-1}$ na produção de biomassa. Por sua vez, a adubação nitrogenada em cobertura promoveu incremento da ordem de $1 \mathrm{t} \mathrm{ha}^{-1}$ de biomassa, na média das duas épocas de cultivo (Tabela 2). Embora não se tenha constatado efeito significativo da adubação de cobertura sobre a produtividade de grãos (Tabela 1), houve estímulo ao desenvolvimento vegetativo do milho pelo fornecimento de mais $\mathrm{N}$ durante a fase inicial de crescimento das plantas, o que normalmente afeta a extração deste e de outros nutrientes.

Considerando as variações no desenvolvimento das plantas (Tabela 2) e na produtividade do milho em cultivos de safrinha, é de se esperar que as quantidades de nutrientes extraídas e exportadas também sejam influenciadas pelos mesmos fatores condicionantes dessas variações. Isso dificulta o estabelecimento de padrões de estado nutricional e de

Tabela 2. Produção de biomassa seca total da parte aérea $\left(\mathrm{kg} \mathrm{ha}^{-1}\right)$ pelo milho safrinha em função da época de cultivo e da adubação nitrogenada em cobertura na região de Rio Verde-GO, 2014.

\begin{tabular}{llll}
\hline & \multicolumn{2}{c}{ Época de semeadura } & \multirow{2}{*}{ Total } \\
\cline { 2 - 3 } & Janeiro & Fevereiro & $14.500 \mathrm{~b}$ \\
\hline Sem adubação de cobertura & 15.760 & 13.240 & $15.571 \mathrm{a}$ \\
Com adubação de cobertura & 17.060 & 14.081 & - \\
\hline Médias & $16.410 \mathrm{~A}$ & $13.660 \mathrm{~B}$ & \\
\hline $\begin{array}{l}\text { Médias seguidas pela mesma letra maiúscula na linha e minúscula na coluna não diferem entre si pelo teste de Scott-Knott a 5\% de } \\
\text { probabilidade. }\end{array}$
\end{tabular}


requerimentos de nutrientes extrapoláveis para diferentes locais, condições climáticas e formas de manejo das lavouras. Não obstante, é importante entender as principais relações de causa-efeito para aprimorar as recomendações técnicas com adequação a cada realidade.
As principais diferenças observadas quanto à extração e exportação de nutrientes pelo milho safrinha foram associadas às influências da época de cultivo e da adubação nitrogenada em cobertura. Não foram evidenciadas interações entre as fontes de variação (Tabelas 3 e 4).

Tabela 3. Resumo da análise de variância dos dados de extração de carbono, macro e micronutrientes pelo milho safrinha.

\begin{tabular}{|c|c|c|c|c|c|c|c|c|c|}
\hline \multicolumn{10}{|l|}{ Quadrado médio } \\
\hline F.V & G.L. & $\mathrm{C}$ & $\mathrm{N}$ & $\mathrm{P}$ & $\mathrm{K}$ & $\mathrm{Ca}$ & $\mathrm{Mg}$ & $\mathrm{S}$ & $\mathrm{Cu}$ \\
\hline Época-E & 1 & $14023676,8 * *$ & $4329,5 * *$ & $405,7^{* *}$ & 219,6 & $70,2 * *$ & $57,7 *$ & $106,6^{* *}$ & $1790,6^{* *}$ \\
\hline Repetição (E) & 6 & 941013,4 & 547,5 & 8,4 & 398,1 & 16,1 & 5,0 & 6,0 & 79,9 \\
\hline NPKsemeadura-S & 3 & 256572,5 & 1067,2 & 10,9 & 395,3 & 20,2 & 12,7 & 4,6 & 70,2 \\
\hline N Cobertura-C & 1 & $5619471,7^{*}$ & $6800,3 * *$ & 30,4 & $1503,4 *$ & $74,0 *$ & $66,3 *$ & $34,1 * *$ & $489,1 * *$ \\
\hline $\mathrm{S} \times \mathrm{C}$ & 3 & 637716,1 & 244,7 & 4,2 & 43,0 & 0,55 & 0,7 & 0,8 & 16,4 \\
\hline $\mathrm{E} \times \mathrm{S}$ & 3 & 227088,6 & 281,4 & 1,4 & 57,3 & 2,0 & 3,7 & 0,7 & 13,5 \\
\hline $\mathrm{E} \times \mathrm{C}$ & 1 & 8606,7 & 97,2 & 1,2 & 252,1 & 1,7 & 9,7 & 0,1 & 14,9 \\
\hline $\mathrm{E} \times \mathrm{S} \times \mathrm{C}$ & 3 & 851699,0 & 256,1 & 2,2 & 170,3 & 4,5 & 3,5 & 1,0 & 39,1 \\
\hline Resíduo & 42 & 905138,8 & 511,9 & 8,5 & 298,2 & 8,7 & 8,7 & 3,1 & 61,4 \\
\hline Total & 63 & & & & & & & & \\
\hline C.V (\%) & & 16,05 & 13,45 & 19,08 & 16,42 & 16,69 & 17,39 & 15,10 & 18,94 \\
\hline
\end{tabular}

* e ** Significativo a 5 e $1 \%$ de probabilidade pelo teste $\mathrm{F}$.

Tabela 4. Resumo da análise de variância dos dados de exportação de carbono, macro e micronutrientes pelo milho safrinha.

\begin{tabular}{|c|c|c|c|c|c|c|c|c|}
\hline \multicolumn{9}{|l|}{ Quadrado médio } \\
\hline F.V. & G.L. & $\mathrm{C}$ & $\mathrm{N}$ & $\mathrm{P}$ & $\mathrm{K}$ & $\mathrm{Ca}$ & $\mathrm{Mg}$ & $\mathrm{S}$ \\
\hline Época-E & 1 & $6516002,8 * *$ & 730,8 & $199,4 * *$ & $1700,2 * *$ & $0,2 * *$ & 0,02 & $9,6^{*}$ \\
\hline Repetição (E) & 6 & 290508,0 & 158,8 & 5,7 & 1,9 & 0,02 & 1,8 & 2,2 \\
\hline NPK semeadura-S & 3 & 96336,8 & 209,0 & 6,3 & 10,1 & 0,01 & 0,7 & 0,8 \\
\hline N Cobertura-C & 1 & 911893,7 & $1110,8 *$ & 13,8 & 14,5 & 0,01 & 0,5 & $8,1^{*}$ \\
\hline $\mathrm{S} \times \mathrm{C}$ & 3 & 3178,9 & 190,4 & 0,9 & 9,0 & 0,03 & 0,5 & 1,13 \\
\hline $\mathrm{E} \times \mathrm{S}$ & 3 & 119380,6 & 423,0 & 0,1 & 11,9 & 0,01 & 0,6 & 2,0 \\
\hline $\mathrm{E} \times \mathrm{C}$ & 1 & 1342,4 & 0,4 & 4,5 & 3,3 & 0,05 & 1,8 & 0,4 \\
\hline $\mathrm{E} \times \mathrm{S} \times \mathrm{C}$ & 3 & 475498,0 & 267,1 & 2,3 & 12,1 & 0,001 & 1,3 & 0,9 \\
\hline Resíduo & 42 & 357514,7 & 235,2 & 5,1 & 15,9 & 0,02 & 1,3 & 1,3 \\
\hline Total & 63 & & & & & & & \\
\hline C.V (\%) & & 20,07 & 13,98 & 19,18 & 17,98 & 25,75 & 21,26 & 16,23 \\
\hline
\end{tabular}

* $\mathrm{e}^{* *}$ Significativo a 5 e $1 \%$ de probabilidade pelo teste $\mathrm{F}$. 


\section{Macronutrientes}

De modo geral, o cultivo com semeadura realizada em janeiro promoveu maior extração e exportação de macronutrientes (Tabela 5). As diferenças de disponibilidade hídrica (Figura 1) indicam que a semeadura em janeiro proporcionou melhores condições para a absorção de nutrientes, formação de espigas e enchimento de grãos, comparativamente ao cultivo semeado em fevereiro, o qual sofreu maior limitação hídrica a partir do início da fase reprodutiva. Fica evidente a vantagem da primeira época quanto ao favorecimento da expressão do potencial produtivo do milho, que assim teve melhor formação e produtividade de grãos, com consequente redistribuição de nutrientes para esse compartimento da planta, resultando em maiores quantidades exportadas.
É interessante notar que a dinâmica do $\mathrm{K}$ na planta parece ter sido mais fortemente influenciada pelas condições climáticas que caracterizaram as duas épocas de cultivo. Observa-se que a extração do nutriente pelo milho não diferiu significativamente em função das épocas, enquanto a exportação nos grãos foi reduzida em cerca de $38 \%$ no cultivo semeado mais tardiamente (Tabela 5). Esse nutriente foi também o que apresentou maior variação entre a proporção exportada em uma e outra época de cultivo.

Os aspectos climáticos são parte da explicação para esses fatos. Ocorre que durante a fase vegetativa nos dois cultivos não houve maior escassez de chuvas (Figura 1), sendo mais nítida tal limitação somente no cultivo tardio a partir do início do florescimento (60 dias após a semeadura). Considerando que cerca de dois terços do total de $\mathrm{K}$ contido na planta é absorvi-

Tabela 5. Extração e exportação de carbono $\left(\mathrm{kg} \mathrm{ha}^{-1}\right)$, macronutrientes $\left(\mathrm{kg} \mathrm{ha}^{-1}\right)$ e micronutrientes $\left(\mathrm{g} \mathrm{ha}^{-1}\right)$, e proporção exportada (\%) pela cultura do milho safrinha, em duas épocas de cultivo (semeadura em janeiro e fevereiro), na região de Rio Verde-GO, 2014.

\begin{tabular}{|c|c|c|c|c|c|c|}
\hline \multirow{2}{*}{ Nutriente } & \multicolumn{2}{|l|}{ Extração } & \multicolumn{2}{|c|}{ Exportação } & \multicolumn{2}{|c|}{ Proporção exportada } \\
\hline & Janeiro & Fevereiro & Janeiro & Fevereiro & Janeiro & Fevereiro \\
\hline $\mathrm{C}$ & $6397,5 \mathrm{a}$ & $5461,3 \mathrm{~b}$ & $3297,8 \mathrm{a}$ & $2659,7 \mathrm{~b}$ & 51 & 49 \\
\hline $\mathrm{N}$ & $176,4 \mathrm{a}$ & $159,9 \mathrm{~b}$ & $113,1 \mathrm{a}$ & $106,3 \mathrm{a}$ & 64 & 66 \\
\hline $\mathrm{P}$ & $17,8 \mathrm{a}$ & $12,7 \mathrm{~b}$ & $13,5 \mathrm{a}$ & $10,0 \mathrm{~b}$ & 76 & 79 \\
\hline K & $103,3 \mathrm{a}$ & $107,0 \mathrm{a}$ & $27,3 \mathrm{a}$ & $17,0 \mathrm{~b}$ & 26 & 16 \\
\hline $\mathrm{Ca}$ & $18,7 \mathrm{a}$ & $16,6 \mathrm{~b}$ & $0,5 \mathrm{~b}$ & $0,6 \mathrm{a}$ & $<1$ & $<1$ \\
\hline $\mathrm{Mg}$ & $17,8 \mathrm{a}$ & $19,9 \mathrm{~b}$ & $5,3 \mathrm{a}$ & $5,3 \mathrm{a}$ & 30 & 27 \\
\hline S & $13,0 \mathrm{a}$ & $10,4 \mathrm{~b}$ & $7,5 \mathrm{a}$ & $6,7 \mathrm{~b}$ & 58 & 64 \\
\hline $\mathrm{Cu}$ & $47 \mathrm{a}$ & $36 \mathrm{~b}$ & $14 \mathrm{~b}$ & $17 \mathrm{a}$ & 30 & 46 \\
\hline $\mathrm{Fe}$ & $1507 \mathrm{a}$ & $1194 b$ & $76 \mathrm{~b}$ & $103 \mathrm{a}$ & 5 & 9 \\
\hline $\mathrm{Mn}$ & $236 \mathrm{a}$ & $194 \mathrm{~b}$ & $32 \mathrm{a}$ & $28 \mathrm{~b}$ & 13 & 14 \\
\hline $\mathrm{Zn}$ & $240 \mathrm{a}$ & $186 \mathrm{~b}$ & $124 \mathrm{a}$ & $120 \mathrm{a}$ & 52 & 65 \\
\hline
\end{tabular}

Para as variáveis extração e exportação, médias seguidas pela mesma letra na linha não diferem entre si pelo teste de Scott-Knott a 5\% de probabilidade. 
do ao longo do período antecedente ao florescimento do milho (Bender et al., 2013), constata-se que não houve restrição na fase de acúmulo do nutriente, justificando a extração similar para as épocas de semeadura em janeiro e fevereiro. Já a menor exportação na segunda época pode ser explicada não apenas pela redução da produtividade, mas, provavelmente, também pela limitada redistribuição do K para os grãos sob condições de deficiência hídrica na fase de formação da espiga e enchimento de grãos.

Embora entre as épocas de semeadura do milho tenha havido diferença em relação à quantidade acumulada de cada nutriente, a magnitude de extração manteve a mesma ordem para os dois cultivos, sendo: $\mathrm{N}>\mathrm{K}>\mathrm{Ca}>\mathrm{Mg}>\mathrm{P}>\mathrm{S}$. Broch \& Ranno (2009), assim como Roscoe \& Miranda (2013), relataram a sequência de extração $\mathrm{N}>\mathrm{K}>\mathrm{P}>\mathrm{Mg}>\mathrm{Ca}>\mathrm{S}$, enquanto Coelho \& Resende (2008) mencionam $\mathrm{N}>\mathrm{K}>\mathrm{P}>\mathrm{Ca}>\mathrm{Mg}$. Pela comparação dessas informações, percebe-se que, à exceção do N e K, que são sempre absorvidos em grandes quantidades (Vergütz \& Novais, 2015), a acumulação dos demais macronutrientes é mais influenciada pelas características peculiares a cada condição de cultivo em safrinha, havendo variação na ordem de extração de $\mathrm{P}, \mathrm{Ca}, \mathrm{Mg}$ e S, conforme a fonte de consulta.

Em relação à exportação nos grãos colhidos, verifica-se que apesar do intenso acúmulo de $\mathrm{K}$ nas plantas, a proporção desse nutriente direcionada para os grãos foi relativamente baixa (Tabela 5), como tipicamente ocorre na cultura do milho (Coelho \& França, 1995; Resende et al., 2014). Comportamento contrário ocorre no caso do $\mathrm{P}$, que, embora não seja acumulado em grande quantidade na planta, é majoritariamente alocado nos grãos, o que resulta em elevado percentual exportado na colheita. No presente trabalho, a ordem de exportação dos macronutrientes foi a seguinte: $\mathrm{N}>\mathrm{K}>\mathrm{P}>\mathrm{S}>\mathrm{Mg}>\mathrm{Ca}$. Essa sequência corrobora as indicações de Bull et al. (1993) para o milho cultivado na safra de verão. Para o milho safrinha, Roscoe \& Miranda (2013) mencionaram que o P (expresso como $\mathrm{P}_{2} \mathrm{O}_{5}$ ) foi o segundo nutriente mais exportado após o N. Essas diferenças podem ser atribuídas a adubações distintas, além da época de semeadura, cultivar e clima durante os estádios de desenvolvimento (Bull et al., 1993), afetando a absorção e exportação dos nutrientes pela cultura.

Já as quantidades de carbono (C) acumuladas nas plantas (Tabela 5) corresponderam a cerca de $40 \%$ da biomassa total produzida pelo milho (Tabela 2). Do carbono que foi incorporado aos tecidos, aproximadamente a metade é removida do sistema pela colheita dos grãos. As quantidades remanescentes na palhada equivaleram, respectivamente, a $3.100 \mathrm{e}$ $2.802 \mathrm{~kg} \mathrm{ha}^{-1} \mathrm{de} \mathrm{C}$ nos cultivos com semeadura em janeiro e fevereiro. Embora não seja requerido nas adubações, o aporte de $\mathrm{C}$ advindo da atividade fotossintética das plantas é fundamental para a sustentabilidade dos sistemas agrícolas por causa do seu papel na constituição da matéria orgânica e atividade biológica do solo, com todas as implicações para a qualidade química e física dos ambientes de produção. Nesse aspecto, cabe enfatizar a importância do milho para o sistema soja-milho safrinha, uma vez que a quantidade de $\mathrm{C}$ incorporada ao solo, oriunda do cultivo da leguminosa, é muito menor (Bayer et al., 2006; Rodrigues Júnior et al., 2009).

Nos tratamentos que receberam a adubação nitrogenada de cobertura, observou-se maior extração de $\mathrm{N}, \mathrm{K}, \mathrm{Ca}, \mathrm{Mg}$ e $\mathrm{S}$ em comparação aos tratamentos sem cobertura (Tabela 6). Porém, apenas N e S apresentaram maiores valores exportados em função da adubação de cobertura. Provavelmente, as diferenças de extração ocorreram em virtude de o nitrogênio 
fornecido em cobertura ter resultado em plantas mais vigorosas e com maior produção de biomassa seca (Tabela 2), o que incrementa a demanda e leva, consequentemente, à maior absorção e acumulação dos nutrientes disponíveis no sistema.

O acúmulo de nitrogênio na parte aérea da planta é de grande importância no momento de enchimento de grãos, já que, nesta fase, o $\mathrm{N}$ absorvido pelas raízes não é suficiente para atender à demanda para formação dos grãos, processo que passa a se valer da redistribuição do nutriente contido nas partes vegetativas (Souza \& Fernandes, 2006). Portanto, o seu fornecimento em cobertura favorece a longevidade das folhas baixeiras e aumenta a quantidade do nutriente disponível ao final do ciclo para compor os grãos.

No caso do enxofre, a maior extração e exportação em função da adubação nitrogenada em cober- tura também pode ser explicada pela sinergia existente entre esses nutrientes (Plessis \& Agenbag, 1994), sugerindo que o fornecimento de $\mathrm{N}$ em cobertura estimularia a absorção de S.

Noutra abordagem comparativa, os valores de extração e exportação de macronutrientes e carbono são representados em base equivalente para cada tonelada de grãos de milho produzida na safrinha, nos cultivos com semeadura em janeiro e fevereiro (Tabela 7). Cabe lembrar que os valores de exportação por tonelada, expressos em $\mathrm{kg} \mathrm{t}^{-1}$, podem também ser interpretados como os teores dos nutrientes presentes nos grãos, cuja unidade de expressão de resultados na análise de laboratório $\left(\mathrm{g} \mathrm{kg}^{-1}\right)$ corresponde à mesma grandeza.

Observa-se que há variações nas taxas de extração e exportação dos nutrientes por tonelada de grãos conforme a época de semeadura do milho sa-

Tabela 6. Extração e exportação de carbono $\left(\mathrm{kg} \mathrm{ha}^{-1}\right)$, macronutrientes $\left(\mathrm{kg} \mathrm{ha}^{-1}\right)$ e micronutrientes $\left(\mathrm{g} \mathrm{ha}^{-1}\right)$, e proporção exportada (\%) pelo milho safrinha, sem (Cob. 0) e com (Cob. 50) adubação nitrogenada em cobertura, na região de Rio Verde-GO, 2014.

\begin{tabular}{lllllll}
\hline \multirow{2}{*}{ Nutriente } & Extração & \multicolumn{3}{c}{ Exportação } & \multicolumn{2}{c}{ Proporção exportada } \\
\cline { 2 - 7 } & Cob. 0 & Cob. 50 & Cob. 0 & Cob. 50 & Cob. 0 & Cob. 50 \\
\hline $\mathrm{C}$ & $5633,1 \mathrm{~b}$ & $6225,7 \mathrm{a}$ & $2859,4 \mathrm{a}$ & $3098,1 \mathrm{a}$ & 51 & 50 \\
$\mathrm{~N}$ & $157,9 \mathrm{~b}$ & $178,5 \mathrm{a}$ & $105,5 \mathrm{~b}$ & $113,8 \mathrm{a}$ & 67 & 64 \\
$\mathrm{P}$ & $14,6 \mathrm{a}$ & $16,0 \mathrm{a}$ & $11,3 \mathrm{a}$ & $12,2 \mathrm{a}$ & 77 & 76 \\
$\mathrm{~K}$ & $100,3 \mathrm{~b}$ & $110,0 \mathrm{a}$ & $21,6 \mathrm{a}$ & $22,6 \mathrm{a}$ & 21 & 20 \\
$\mathrm{Ca}$ & $16,6 \mathrm{~b}$ & $18,8 \mathrm{a}$ & $0,5 \mathrm{a}$ & $0,5 \mathrm{a}$ & $<1$ & $<1$ \\
$\mathrm{Mg}$ & $15,9 \mathrm{~b}$ & $17,9 \mathrm{a}$ & $5,2 \mathrm{a}$ & $5,4 \mathrm{a}$ & 33 & 30 \\
$\mathrm{~S}$ & $11,0 \mathrm{~b}$ & $12,4 \mathrm{a}$ & $6,8 \mathrm{~b}$ & $7,5 \mathrm{a}$ & 62 & 60 \\
$\mathrm{Cu}$ & $39 \mathrm{~b}$ & $44 \mathrm{a}$ & $15 \mathrm{a}$ & $16 \mathrm{a}$ & 33 & 32 \\
$\mathrm{Fe}$ & $1295 \mathrm{~b}$ & $1407 \mathrm{a}$ & $87 \mathrm{a}$ & $93 \mathrm{a}$ & 5 & 6 \\
$\mathrm{Mn}$ & $203 \mathrm{~b}$ & $227 \mathrm{a}$ & $29 \mathrm{a}$ & $31 \mathrm{a}$ & 12 & 12 \\
$\mathrm{Zn}$ & $206 \mathrm{a}$ & $219 \mathrm{a}$ & $117 \mathrm{a}$ & $127 \mathrm{a}$ & 52 & 54 \\
\hline
\end{tabular}

Para as variáveis extração e exportação, médias seguidas pela mesma letra na linha não diferem entre si pelo teste de Scott-Knott a 5\% de probabilidade. 
frinha (Tabela 7), o que pode estar relacionado a fatores climáticos ligados à disponibilidade hídrica influenciando os processos de absorção radicular (Raij, 2011), acúmulo na parte aérea e redistribuição dos diferentes nutrientes para os grãos, a exemplo do que foi anteriormente discutido em relação ao potássio. No caso das taxas de exportação, pode também haver influência dos efeitos de concentração e diluição de nutrientes (Jarrel \& Beverly, 1981) nos grãos, decorrentes da menor ou maior produtividade obtida em função da época de cultivo.

De modo geral, nos dois cultivos de milho que constituíram o presente estudo, a quantidade de macronutrientes extraídas e exportadas para cada tonelada de grãos produzida (Tabela 7) são inferiores aos dados reportados na literatura. Para a extração de N, $\mathrm{P}$ e K relatada em publicações relacionadas ao milho safrinha, os intervalos variam de 16,7 a $28 ; 2,3$ a 4,5; e 14,1 a $20,8 \mathrm{~kg} \mathrm{t}^{-1}$, respectivamente (Coelho \& Re- sende, 2008; Roscoe \& Miranda, 2013; Duarte et al., 2013). Em relação à exportação, Roscoe \& Miranda (2013) mencionaram valores de 15,8; 3,8; e 4,8 kg $\mathrm{t}^{-1}$ de N, P e K, respectivamente. Duarte et al. (2013) informaram taxas de exportação de 15,0; 3,6; 4,7; e $1,2 \mathrm{~kg}$ de N, P, K e S por tonelada de grãos produzida. Todavia, é importante ponderar que os dados disponibilizados nas publicações citadas acima nem sempre se referem a cultivos de milho na safrinha.

De acordo com Bender et al. (2013), a remoção de nutrientes pelo milho é variável em função dos genótipos utilizados e dos ambientes de cultivo. Resende et al. (2014) evidenciaram a tendência de decréscimo nos valores reportados em trabalhos brasileiros publicados mais recentemente em comparação aos mais antigos. Essa tendência sugere prováveis ganhos na eficiência de utilização de nutrientes por genótipos modernos de milho cultivados em sistemas mais tecnificados.

Tabela 7. Extração e exportação de carbono $(\mathrm{kg})$, macronutrientes $(\mathrm{kg})$ e micronutrientes $(\mathrm{g})$ por tonelada de grãos produzida pelo milho safrinha, em duas épocas de cultivo (semeadura em janeiro e fevereiro), na região de Rio Verde-GO, 2014.

\begin{tabular}{|c|c|c|c|c|c|c|}
\hline \multirow{2}{*}{ Nutriente } & \multicolumn{2}{|c|}{ Extração por tonelada de grãos } & \multirow{2}{*}{$\underline{\text { Média }}$} & \multicolumn{2}{|c|}{ Exportação por tonelada de grãos } & \multirow{2}{*}{ Média } \\
\hline & Janeiro & Fevereiro & & Janeiro & Fevereiro & \\
\hline $\mathrm{C}$ & 742,4 & 786,7 & 764,6 & 377,0 & 382,3 & 379,7 \\
\hline $\mathrm{N}$ & 20,4 & 23,0 & 21,7 & 13,0 & 15,3 & 14,2 \\
\hline $\mathrm{P}$ & 2,0 & 1,8 & 1,9 & 1,5 & 1,4 & 1,5 \\
\hline $\mathrm{K}$ & 12,1 & 15,4 & 13,8 & 3,1 & 2,4 & 2,8 \\
\hline $\mathrm{Ca}$ & 2,2 & 2,4 & 2,3 & 0,05 & 0,08 & 0,07 \\
\hline $\mathrm{Mg}$ & 2,1 & 2,3 & 2,2 & 0,6 & 0,8 & 0,7 \\
\hline S & 1,5 & 1,5 & 1,5 & 0,9 & 1,0 & 1,0 \\
\hline $\mathrm{Cu}$ & 5 & 5 & 5 & 2 & 2 & 2 \\
\hline $\mathrm{Fe}$ & 178 & 173 & 176 & 9 & 15 & 12 \\
\hline $\mathrm{Mn}$ & 28 & 28 & 28 & 4 & 4 & 4 \\
\hline $\mathrm{Zn}$ & 27 & 27 & 27 & 14 & 17 & 16 \\
\hline
\end{tabular}

Para conversão de $\mathrm{P}$ em $\mathrm{P}_{2} \mathrm{O}_{5}$ e K em $\mathrm{K}_{2} \mathrm{O}$, multiplicar o valor da tabela por 2,29 e 1,2, respectivamente. 
Na prática, as mudanças nos padrões de exportação de nutrientes, ao longo do tempo ou de uma região produtora para outra, têm implicações para o dimensionamento da adubação de manutenção, uma vez que se deve considerar os índices de exportação como critério na tomada de decisão (Cruz et al., 2011), especialmente em se tratando da modalidade de cultivo na safrinha. Nesse contexto, a menor magnitude de exportação de macronutrientes observada nos cultivos em Rio Verde-GO, comparativamente às referências disponíveis na literatura, constitui informação relevante para o manejo da fertilidade do solo na região e sinaliza para a conveniência de se aferir localmente os padrões de demanda nutricional do milho safrinha em outras regiões produtoras.

Em princípio, as menores taxas de exportação confirmam a possibilidade de se trabalhar com doses relativamente baixas de fertilizantes, atendendo satisfatoriamente a demanda do milho safrinha cultivado em solos de fertilidade corrigida. Essa alternativa é reforçada pela ausência de resposta em produtividade de grãos frente aos tratamentos com adubação NPK na semeadura e com $\mathrm{N}$ em cobertura nos dois cultivos avaliados (Tabela 1).

\section{Micronutrientes}

De forma análoga ao observado para os macronutrientes, o cultivo com semeadura realizada mais cedo, no mês de janeiro, resultou em maior extração dos micronutrientes se comparado ao cultivo semeado no mês de fevereiro (Tabela 5), provavelmente pela condição de pluviosidade mais favorável no primeiro caso (Figura 1).

Também a adubação nitrogenada em cobertura promoveu maior absorção dos micronutrientes (Tabela 6), de modo similar ao que se verificou para os ma- cronutrientes. A exceção foi o Zn, que não apresentou diferença significativa de acúmulo, embora em valor absoluto a absorção tenha sido incrementada com a cobertura nitrogenada. Novamente, o aumento da produção de biomassa por causa dessa adubação (Tabela 2) é o que justificaria a maior extração de micronutrientes pelo milho nesse caso.

Com relação à exportação, a época de cultivo não teve influência igual sobre todos micronutrientes avaliados. A semeadura em janeiro resultou em quantidades significativamente menores de $\mathrm{Cu}$ e $\mathrm{Fe}$ removidas nos grãos colhidos, maior quantidade de Mn, e foi indiferente no caso do Zn (Tabela 5). Já a adubação de cobertura com nitrogênio não modificou os níveis de exportação desses micronutrientes (Tabela 6).

Pelos dados obtidos, verifica-se que o Fe foi o micronutriente absorvido pelo milho safrinha em maior quantidade, seguido de $\mathrm{Mn}$ e $\mathrm{Zn}$, que foram acumulados em quantidades semelhantes e bem superiores ao mensurado para o $\mathrm{Cu}$. Apesar da maior extração de Fe, este foi o micronutriente com menor taxa de exportação $(<10 \%)$, permanecendo, portanto, majoritariamente nos restos culturais. Por sua vez, o $\mathrm{Zn}$ teve a maior taxa de exportação $(>50 \%)$, seguido por $\mathrm{Cu}$ e $\mathrm{Mn}$. A ordem de extração $\mathrm{Fe}>\mathrm{Mn} \geq \mathrm{Zn}>\mathrm{Cu}$, assim como a elevada exportação de $\mathrm{Zn}$, corroboram as indicações de Roscoe \& Miranda (2013).

É interessante notar que, embora a extração absoluta tenha sido maior no primeiro cultivo (Tabela 5), as taxas de extração relativizadas pela produtividade de grãos mantiveram-se mais ou menos constantes entre os dois cultivos (Tabela 7). Por outro lado, tanto a porcentagem exportada de micronutrientes (Tabela 5) quanto a taxa de exportação por tonelada de grãos colhida (Tabela 7) foram mais elevadas no segundo cultivo, o qual sofreu maior restrição hídrica após a 
fase de polinização (Figura 1). Esse comportamento sugere que a condição de estresse hídrico pode ter induzido maior redistribuição desses micronutrientes catiônicos das partes vegetativas para os grãos.

As taxas médias de exportação de micronutrientes por tonelada produzida (Tabela 7), que também equivalem aos teores nos grãos $\left(\mathrm{mg} \mathrm{kg}^{-1}\right)$, foram menores que as relatadas por Bender et al. (2013), que, na média de seis híbridos e dois locais com produtividade ao redor de $12 \mathrm{t} \mathrm{ha}^{-1}$ nos Estados Unidos, encontraram taxas de 3,4;20,7;6,0; e 25,7 $\mathrm{g} \mathrm{t}^{-1}$ para $\mathrm{Cu}, \mathrm{Fe}, \mathrm{Mn}$ e $\mathrm{Zn}$, respectivamente. No Brasil, Broch \& Ranno (2009) reportaram exportação em milho safrinha da ordem de 1,2; 11,6; 6,1; e 27,6 $\mathrm{g} \mathrm{t}^{-1}$ para $\mathrm{Cu}$, $\mathrm{Fe}, \mathrm{Mn}$ e Zn, respectivamente.

Os resultados do presente estudo levam à constatação de que a demanda nutricional do milho safrinha, expressa pela extração e exportação de macro e micronutrientes, podem variar em razão dos condicionantes climáticos e do manejo que modulam o crescimento de plantas e a produtividade final a cada cultivo. As diferenças observadas nas taxas de extração e exportação em relação às informações disponíveis na literatura comprovam a necessidade de se particularizar a quantificação dessas taxas em âmbito regional ou local, como forma de se aprimorar os critérios para tomada de decisões de manejo visando maior eficiência produtiva e rentabilidade no sistema soja-milho safrinha.

\section{Conclusões}

O desenvolvimento e a extração de nutrientes pelo milho safrinha são influenciados pela época de cultivo, assim como pela adubação nitrogenada em cobertura, sem, contudo, ser afetados pela adubação NPK realizada na semeadura.
Há maior produção de biomassa seca e produtividade de grãos com a semeadura em janeiro em comparação a fevereiro. O cultivo na primeira época e o nitrogênio em cobertura resultam em maior extração da maioria dos nutrientes, sem necessariamente ocasionar maiores taxas de exportação com a colheita dos grãos.

Em média, a exportação por tonelada de grãos produzida foi de 14,$2 ; 1,5 ; 2,8 ; 0,07 ; 0,7$ e $1,0 \mathrm{~kg}$ de $\mathrm{N}, \mathrm{P}, \mathrm{K}, \mathrm{Ca}, \mathrm{Mg}$ e $\mathrm{S}$; e de 2; 12; 4; e $16 \mathrm{~g}$ de $\mathrm{Cu}, \mathrm{Fe}$, $\mathrm{Mn}$ e $\mathrm{Zn}$, respectivamente. Esses valores implicam doses relativamente baixas de fertilizantes na adubação de manutenção para repor a exportação na colheita do milho safrinha.

\section{Agradecimento}

À Fapemig, pela concessão da bolsa de mestrado do primeiro autor.

\section{Referências}

BAYER, C.; MARTIN-NETO, L.; MIELNICZUK, J.; PAVINATO, A.; DIECKOW, J. Carbon sequestration in two Brazilian Cerrado soils under no-till. Soil and Tillage Research, Amsterdam, v. 86, n. 2, p. 237-245, 2006. DOI: 10.1016/j.still.2005.02.023.

BENDER, R. R.; HAEGELE, J. W.; RUFFO, M. L.; BELOW, F. E. Nutrient uptake, partitioning, and remobilization in modern, transgenic insect-protected maize hybrids. Agronomy Journal, Madison, v. 105, n. 1, p. 161-170, 2013.

DOI: 10.2134 /agronj2012.0352.

BROCH, D. L.; RANNO, S. K. Fertilidade do solo, adubação e nutrição da cultura do milho safrinha. In: TECNOLOGIA e produção: milho safrinha e culturas de inverno. 5. ed. Maracaju: Fundação MS, 2009. p. 5-29. 
BULL, L. T. Nutrição mineral do milho. In: BÜLL, L. T.; CANTARELLA, H. Cultura do milho: fatores que afetam a produtividade. Piracicaba: POTAFOS, 1993. p. 63-146.

CANTARELLA, H. Calagem e adubação do milho. In: BÜLL, L. T.; CANTARELLA, H. Cultura do milho: fatores que afetam a produtividade. Piracicaba: POTAFOS, 1993. p. 147-198.

COELHO, A. M.; RESENDE, A. V. de. Exigências nutricionais e adubação do milho safrinha. Sete Lagoas: Embrapa Milho e Sorgo, 2008. 10 p. (Embrapa Milho e Sorgo. Circular Técnica, 111).

COELHO, A. M.; FRANCA, G. E.de. Nutrição e adubação. In: SEJA o doutor do seu milho. 2. ed. aum. Piracicaba: POTAFOS, 1995. p. 1-9. (Arquivo do Agrônomo, 2).

CONAB. Companhia Nacional de Abastecimento. Acompanhamento da safra brasileira: grãos: safra 2015/16: quinto levantamento. Brasília, DF, 2016.

CRUZ, J. C.; SILVA, G. H.; PEREIRA FILHO, I. A.; GONTIJO NETO, M. M.; MAGALHÃES, C. Sistema de produção de milho safrinha de alta produtividade. Sete Lagoas: Embrapa Milho e Sorgo, 2011. 10 p. (Embrapa Milho e Sorgo. Circular Técnica, 160).

DUARTE, A. P.; KURIHARA, C. H.; CANTARELlA, H. Adubação de milho safrinha em consórcio com braquiária. In: CECCON, G. (Ed.). Consórcio milho-braquiária. Brasília, DF: Embrapa, 2013. p. 115-144

DUARTE, A. P.; CANTARELlA, H. Adubação em sistemas de produção de soja e milho safrinha. In: SEMINÁRIO NACIONAL MILHO SAFRINHA, 9., 2007, Dourados, MS. Milho safrinha: rumo à estabilidade: anais. Dourados, MS: Embrapa Agropecuária Oeste, 2007. p. 44-61. (Embrapa Agropecuária Oeste. Documentos, 89).

FERREIRA, D. F. Sisvar: a computer statistical analysis system. Ciência e Agrotecnologia, Lavras, v. 35, n. 6, p. 1039-1042, 2011.

DOI: 10.1590/S1413-70542011000600001.
GALVÃO, J. C. C.; TROGELlO, E.; PEREIRA, L. P. L. Milho segunda safra. In: GALVÃO, J. C. C.; BORÉM, A.; PIMENTEL, M. A. G. (Ed.). Milho: do plantio à colheita. Viçosa, MG: UFV, 2015. p. 207-223.

JARREL, W. M.; BEVERLY, R. B. The dilution effect in plant nutrition studies. Advances in Agronomy, New York, v. 34, p. 197-224, 1981.

DOI: $10.1016 / \mathrm{S} 0065-2113(08) 60887-1$.

KAPPES, C.; ZANCANARO, L. Manejo da fertilidade do solo em sistemas de produção no Mato Grosso. In: KARAM, D.; MAGALHÃES, P. C. Eficiência nas cadeias produtivas e abastecimento global. Sete Lagoas: Associação Brasileira de Milho e Sorgo, 2014. p. 358-381.

NASCIMENTO, F. M.; BICUDO, S. J.; RODRIGUES, J. G. L.; FURTADO, M. B.; SÉRGIO CAMPOS, S. Produtividade de genótipos de milho em resposta à época de semeadura. Revista Ceres, Viçosa, MG, v. 58, n. 2, p. 193201, 2011. DOI: 10.1590/S0034-737X2011000200010.

PLESSIS, J. P.; AGENBAG, G. A. Reaction of two wheat cultivars to nitrogen and sulphur fertilizer in the Swartland: I. Vegetative growth, nitrogen and sulphur uptake and concentration in the plant. South African Journal of Plant and Soil, Pretoria, v. 11, n. 4, p. 163-169, 1994.

RAIJ, B. Van. Fertilidade do solo e manejo de nutrientes. Piracicaba: International Plant Nutrition Institute, 2011. 420 p.

RESENDE,A.V.; MARS, G.; SIMÃO,E.P.; GUIMARÃES, P. E. O.; GUIMARÃES, L. J. M. Compartimentalização e dinâmica de potássio em plantas de milho. In: CONGRESO LATINOAMERICANO DE LA CIENCIA DEL SUELO, 20.; CONGRESO PERUANO DE LA CIENCIA DEL SUELO, 16., 2014, Cusco. Educar para preservar el suelo y conservar la vida en la tierra: [anales]. Cusco: Sociedade Latinoamericana de la Sciencia del Suelo: Sociedade Peruana de la Sciencia del Suelo, 2014.

RODRIGUES JÚNIOR, D. J.; TORRES, J. L. R.; PEREIRA, M. G.; FABIAN, A. J. Produção de grãos e decomposição dos resíduos culturais de milho e soja 
em função das plantas de cobertura. In: SEMINÁRIO INICIAÇÃO CIENTÍFICA-IFTM，2., 2009, Uberaba. Anais... Uberaba: Instituto Federal de Educação, Ciência e Tecnologia do Triângulo Mineiro, 2009. p. 1-7.

ROSCOE, R.; MIRANDA, R. de A. S. Manejo da adubação do milho safrinha. Maracaju: Fundação MS, 2013. Disponível em: <http://www.fundacaoms. org.br/base/ www/ fundacao ms.org.br/media/ attachments/49/49/5399b261378ac99ed5725dd348adae fdb4f8a df4176b1_capitulo-01_ manejo -e-adubacaodo-milho-safrinha.pdf>. Acesso em: 13 set. 2015.

SILVA, F. C. da. (Ed.). Manual de análises químicas de solos, plantas e fertilizantes. 2. ed. Brasília, DF: Embrapa Informação Tecnológica; Rio de Janeiro: Embrapa Solos, 2009. $627 \mathrm{p}$.
SOUZA, S. R.; FERNANDES, M. S. Nitrogênio. In: FERNANDES, M. S. Nutrição mineral de plantas. Viçosa, MG: Sociedade Brasileira de Ciência do Solo, 2006. p. 215-252.

VERGÜTZ, L.; NOVAIS, R. F. Recomendação de corretivos e adubação. In: GALVÃO, J. C. C.; BORÉM, A.; PIMENTEL, M. A. (Ed.). Milho: do plantio à colheita. Viçosa, MG: UFV, 2015. p. 108-136.

VILHEGAS, A. C. G.; VIDIGAL FILHO, P. S.; SCAPIM, C. A.; GONÇALVES-VIDIGAL, M. C.; BRACCINI, A. de L.; SAGRILO, E. Efeito de épocas de semeadura e estabilidade de híbridos de milho em plantios de safrinha no noroeste do Paraná. Bragantia, Campinas, v. 60, n. 1, p. 45-51, 2001.

DOI: $10.1590 / \mathrm{S} 0006-87052001000100006$. 